\title{
LMWF5A suppresses cytokine release by modulating select inflammatory transcription factor activity in stimulated PBMC
}

\author{
Gregory Thomas ${ }^{1}$, Elizabeth Frederick', Lisa Thompson' ${ }^{1}$, Raphael Bar-Or 1,2,3,4, , Yetti Mulugeta', \\ Melissa Hausburg $2,3,4,5$, Michael Roshon ${ }^{4}$, Charles Mains ${ }^{5}$ and David Bar-Or $2,3,4,5,6^{*}$
}

\begin{abstract}
Background: Dysregulation of transcription and cytokine expression has been implicated in the pathogenesis of a variety inflammatory diseases. The resulting imbalance between inflammatory and resolving transcriptional programs can cause an overabundance of pro-inflammatory, classically activated macrophage type 1 (M1) and/or helper T cell type 1 (Th1) products, such as IFNY, TNFa, IL1- $\beta$, and IL12, that prevent immune switching to resolution and healing. The low molecular weight fraction of human serum albumin (LMWF5A) is a novel biologic drug that is currently under clinical investigation for the treatment of osteoarthritis and the hyper-inflammatory response associated with COVID19. This study aims to elucidate transcriptional mechanisms of action involved with the ability of LMWF5A to reduce pro-inflammatory cytokine release.
\end{abstract}

Methods: ELISA arrays were used to identify cytokines and chemokines influenced by LMWF5A treatment of LPSstimulated peripheral blood mononuclear cells (PBMC). The resulting profiles were analyzed by gene enrichment to gain mechanistic insight into the biologic processes and transcription factors (TFs) underlying the identified differentially expressed cytokines. DNA-binding ELISAs, luciferase reporter assays, and TNFa or IL-1 $\beta$ relative potency were then employed to confirm the involvement of enriched pathways and TFs.

Results: LMWF5A was found to significantly inhibit a distinct set of pro-inflammatory cytokines (TNFa, IL-1ß, IL-12, CXCL9, CXCL10, and CXCL11) associated with pro-inflammatory M1/Th1 immune profiles. Gene enrichment analysis also suggests these cytokines are, in part, regulated by NF-KB and STAT transcription factors. Data from DNA-binding and reporter assays support this with LMWF5A inhibition of STAT1 a DNA-binding activity as well as a reduction in overall NF-KB-driven luciferase expression. Experiments using antagonists specific for the immunomodulatory and NF-kB/STAT-repressing transcription factors, peroxisome proliferator-activated receptor (PPAR) $y$ and aryl hydrocarbon receptor (AhR), indicate these pathways are involved in the LMWF5A mechanisms of action by reducing LMWF5A drug potency as measured by TNFa and IL-1 $\beta$ release.

Conclusion: In this report, we provide evidence that LMWF5A reduces pro-inflammatory cytokine release by activating the immunoregulatory transcription factors PPARY and AhR. In addition, our data indicate that LMWF5A suppresses NF-KB and STAT1 a pro-inflammatory pathways. This suggests that LMWF5A acts through these mechanisms to decrease pro-inflammatory transcription factor activity and subsequent inflammatory cytokine production.

\footnotetext{
*Correspondence: davidbme49@gmail.com

${ }^{2}$ Trauma Research Department, Swedish Medical Center, 501 E. Hampden Ave. Rm 4-454, Englewood, CO 80113, USA

Full list of author information is available at the end of the article
}

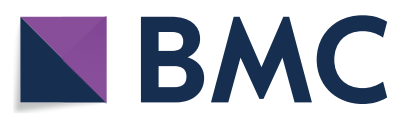

(c) The Author(s) 2020. This article is licensed under a Creative Commons Attribution 4.0 International License, which permits use, sharing, adaptation, distribution and reproduction in any medium or format, as long as you give appropriate credit to the original author(s) and the source, provide a link to the Creative Commons licence, and indicate if changes were made. The images or other third party material in this article are included in the article's Creative Commons licence, unless indicated otherwise in a credit line to the material. If material is not included in the article's Creative Commons licence and your intended use is not permitted by statutory regulation or exceeds the permitted use, you will need to obtain permission directly from the copyright holder. To view a copy of this licence, visit http://creativeco mmons.org/licenses/by/4.0/. The Creative Commons Public Domain Dedication waiver (http://creativecommons.org/publicdomain/ zero/1.0/) applies to the data made available in this article, unless otherwise stated in a credit line to the data. 
Keywords: LMWF5A, PPARy, AhR, NF-kb, STAT, Transcription, Cytokines, Chemokines

\section{Background}

Dysregulation of transcription and the expression of inflammatory proteins has been implicated in the pathogenesis of a variety of chronic diseases including arthritis, atherosclerosis, diabetes, pulmonary fibrosis, kidney disease, and inflammatory bowel disease [1]. Although these conditions exhibit a range of clinical symptoms, they all involve an overactivation of the immune response and/or an inability of the immune response to progress towards resolution and healing. Under normal circumstances, the immune system transitions through sequentially triggered sets or profiles of functionally related genes, known as expression programs, that drive the cellular activity and cell-type identity of immune cells in a return to homeostasis [2]. Early damage or infection signals induce the genetic orientation of classically activated type 1 macrophages (M1) and CD4+ helper type $1 \mathrm{~T}$-cell (Th1) subsets, which produce pro-inflammatory cytokines and chemokines such as IFN $\gamma$, TNF $\alpha$, IL1- $\beta$, and IL12 [3]. Once the insult has been eliminated, biologic feedback systems then promote the active conversion of immune cells to alternatively activated type 2 macrophages (M2) or CD4+helper type 2 (Th2)/regulatory (Treg) T-cell subsets, transcriptionally programmed to produce antiinflammatory mediators that dampen the inflammatory response and trigger a switch into resolution and healing phases [2, 3]. However, chronic inflammation can manifest under conditions where pro-inflammatory programs sustain the production of cytokine and/or resolving programs fail to eventuate [4].

Central to this level of regulation is the activity of transcription factors (TFs). Biochemical cascades, ushered by specific transmembrane and intracellular receptorligand interactions, evoke the transcription of target genes through the binding of TFs to cognate sequences located in DNA promoter regions [5]. Ultimately, cellular gene expression programs result from the complex interplay between multiple transcription factors and cell-specific regulatory machinery acting together at promoter elements in response to the microenvironment signals received [6]. This complexity enables the immune system to pivot and direct gene expression programs that are specifically crafted for each challenge or phase of the inflammatory response. Moreover, a large body of evidence demonstrates that DNA-binding motifs for TFs such as activator protein 1 (AP-1), nuclear factor kappa-light-chain-enhancer of activated B cells (NF-kB), and signal transducer and activator of transcription proteins (STAT) are over-represented in the promoters of pro-inflammatory genes, suggesting that inflammatory signaling is intimately linked to these regulatory proteins [6]. In support of this, exaggerated and protracted NF- $\mathrm{KB}$ and/or STAT signaling has been linked to chronic inflammation and many of the diseases listed above $[7,8]$. It is also now well established that these TFs contribute to the production of pro-inflammatory M1/Th1 gene signatures and if left unchecked, can lead to excessive immune activation and tissue damage $[9,10]$. Treatments that modulate or interrupt pro-inflammatory TFs may shift the overall response towards homeostasis and provide medical benefits to patients suffering from both acute and chronic inflammatory diseases.

To orchestrate the switching of inflammation to resolution programs and promote healing, transcriptional machinery has evolved that functions to suppress inflammatory signaling pathways [2]. Two such metabolicassociated TFs are peroxisome proliferator-activated receptor (PPAR) $\gamma$ and aryl hydrocarbon receptor (AhR) [11]. These ligand-activated TFs have been shown to aid in coordinating the differentiation of anti-inflammatory and regulatory immune cell phenotypes while, at the same time, repressing the expression of proinflammatory cytokines from M1 macrophages [11, 12]. Pharmacologically activating these proteins has proven successful at reducing inflammation by both reducing the DNA-binding potential of pro-inflammatory TFs as well as modulating the activity of repressor and/or cofactor molecules [13-15]. More importantly, clinical application and repositioning of PPAR $\gamma$ and AhR agonists has shown promise in the treatment of chronic inflammation and cancer $[16,17]$.

The low molecular weight fraction of human serum albumin (LMWF5A) is a novel anti-inflammatory biologic drug that has demonstrated clinical efficacy with reduced pain and improved function in osteoarthritis of the knee, a chronic inflammatory condition, across multiple randomized, vehicle-controlled, double-blinded human trials [18-20]. The potential benefits of LMWF5A as an immunomodulatory therapeutic are also denoted in an observed delay in the need for total knee replacement for severe osteoarthritis trial participants in a 3-year follow-up study [21]. Based on these observations, LMWF5A may serve as an immunomodulatory agent for the treatment of a variety of inflammatory diseases. In fact, clinical studies have been launched to investigate the use of LMWF5A to treat the systemic inflammatory response syndrome and respiratory distress associated with COVID-19. 
Previous in vitro investigations suggest that the clinical effects of LMWF5A may result from the transcriptional modulation of inflammatory mediators. For example, LMWF5A treatment of lipopolysaccharide (LPS)stimulated peripheral blood mononuclear cells (PBMC) reduces TNF $\alpha$ transcription and release, concomitant with increased transcription and expression of COX2, as compared to saline-treated controls [22, 23]. In addition, phorbol 12-myristate 13-acetate (PMA)-differentiated THP-1 macrophages exhibit cytokine expression profiles and transcriptional patterns reflective of a switch from M1 to M2 polarization status when stimulated with LPS in the presence of LMWF5A [24]. Interestingly, LMWF5A also demonstrates an ability to transcriptionally modulate other cell functions; for example, chondrogenic differentiation $[25,26]$ and the homing/migratory potential of bone marrow derived mesenchymal stem cells [25]. Thus, we hypothesized that the mechanisms of action of LMWF5A involve the activation of regulatory transcription factors critical to both immune cell activation and differentiation.

To test this hypothesis, cytokine arrays and bioinformatic analysis were applied to the LPS-stimulated PBMC model utilized in our preceding studies, with the aim of identifying cellular and molecular mechanisms responsible for the observed ability of LMWF5A to influence transcription and protein expression. Identified in silico pathways were examined with pathway-specific pharmacologic antagonists and transcription factor/DNA-binding assays to elucidate mechanisms of action involved with the ability of LMWF5A to inhibit key pro-inflammatory cytokines. In this report, we provide evidence that LMWF5A activates the immunoregulatory transcription factors PPAR $\gamma$ and AhR as well as suppresses the classical NF- $\mathrm{kB}$ and STAT $1 \alpha$ pro-inflammatory signaling pathways. These data provide biologic rationale for the anti-inflammatory properties of LMWF5A and suggests LMWF5A could be a therapeutic treatment for a variety of inflammatory conditions.

\section{Methods}

\section{Materials}

Cell culture reagents were purchased from Gibco, ThermoFisher Scientific (Waltham, MA), and all other reagents were obtained from MilliporeSigma (St. Louis, MO) unless otherwise stated. 5\% human serum albumin (Octapharma, Hoboken, NJ) was used to produce LMWF5A. $0.9 \%(\mathrm{w} / \mathrm{v})$ sodium chloride was obtained from KD Medical (Columbia, MD). $100 \mathrm{mM}$ stock solutions of GW9662 and $\mathrm{CH} 223191$ were prepared in DMSO and stored at $-80{ }^{\circ} \mathrm{C}$ prior to use. ELISAs for TNF $\alpha$ (catalog\# DTA00D) and IL-1 $\beta$ (catalog\# SLB50) were purchased from ThermoScientific and R\&D systems (Minneapolis, $\mathrm{MN}$ ), respectively.

\section{PBMC culture and experimental treatment}

Commercially available frozen human peripheral blood mononuclear cells (Zen-Bio, Research Triangle Park, NC) from a single, strong LMWF5A response donor were used for the ex vivo experiments described in this report. Cell vials stored in liquid nitrogen were thawed using a Thawstar Automated Cell Thawing System (BioLife Solutions, Bothell, WA) and then transferred dropwise to RPMI 1640 medium containing 10\% human AB serum, $1 \%$ penicillin-streptomycin (Pen/Strep), and $2 \mathrm{U} / \mathrm{mL}$ RNase-free DNase (ThermoScientific). The resulting cell suspensions were centrifuged (at $1000 \mathrm{rpm}$ for $10 \mathrm{~min}$ ) and the medium was replaced with RPMI 1640 supplemented with $20 \%$ fetal bovine serum, 2\% Pen/Strep, $1 \%$ sodium bicarbonate $7.5 \%$ solution, $1 \% 100 \mathrm{mM}$ sodium pyruvate, 1\% 100X MEM non-essential amino acid solution, and 1\% $200 \mathrm{mM}$ L-glutamine. For experimental treatments, cell suspensions were adjusted to $2 \times 10^{6}$ cells/mL using the described culture medium and then mixed with equal volumes of sterile $0.9 \%$ sodium chloride or LMWF5A and incubated at $37{ }^{\circ} \mathrm{C}$ and $5 \% \mathrm{CO}_{2}$ for one hour. Cells were stimulated with O55:B5 lipopolysaccharide (final concentration of $100 \mathrm{ng} / \mathrm{ml}$; catalog\# L6529) and incubated for an additional $24 \mathrm{~h}$ before subsequent analysis.

\section{Cytokine arrays}

To evaluate large-scale release of cytokines and chemokines, saline- or LMWF5A-treated, LPS-stimulated PBMC were cultured as described above in triplicate in $0.8-\mathrm{mL}$ final reaction volumes for $24 \mathrm{~h}$ and then centrifuged $(1000 \mathrm{rpm}, 10 \mathrm{~min})$. The resulting conditioned mediums were combined, and cytokine release was analyzed using Human Cytokine ELISA Plate Array IV (Signosis, Santa Clara, CA; catalog\# EA-4015) following the manufacturer's instructions, with optical density (OD) measured at $450 \mathrm{~nm}$ using an ELx808 Absorbance Microplate Reader (Biotek Instruments, Winooski, VT). Fold change in blank-subtracted OD measurements of LMWF5A-treated, LPS-stimulated cultures versus saline-treated, LPS-stimulated groups were then calculated for three independent experiments. Enrichment analysis of differentially abundant cytokines was performed using the web-based applications Enricher (https ://amp.pharm.mssm.edu/Enrichr/) and Chea3 (https:// amp.pharm.mssm.edu/chea3/).

\section{Transcription factor DNA-binding ELISAs}

To establish the activity of select transcription factors, saline- or LMWF5A-treated, unstimulated or 
LPS-stimulated PBMC were cultured as described above in a final reaction volume of $25 \mathrm{~mL}$ for $24 \mathrm{~h}$ and then centrifuged at $1000 \mathrm{rpm}$ for $10 \mathrm{~min}$. Nuclear protein was extracted from the cell pellets using a nuclear extraction kit (Active Motif, Carlsbad, CA), and the captured protein concentration was determined using Pierce detergent-compatible Bradford reagent (ThermoScientific). DNA-binding ELISAs (Active Motif) were then performed for NF- $\mathrm{kB}$ subunits (catalog\# 43,296), AP-1 subunits (catalog\# 44,296), and STAT (catalog\# 42,296) using $2 \mu \mathrm{g}, 5 \mu \mathrm{g}$, and $5 \mu \mathrm{g}$ total protein per reaction, respectively, following the manufacturer's recommendations.

\section{Relative potency bioassays}

To determine the potency of LMWF5A test samples, LPS-stimulated PBMC were cultured as described above in quadruplicate in $110 \mu \mathrm{L}$ final reaction volumes, blocked to protect against location bias, in 96-well tissue culture plates with five, 1.4-fold serial dilutions of LMWF5A (prepared in saline). After $24 \mathrm{~h}$, the plates were centrifuged at 1,000 rpm for $10 \mathrm{~min}$, and TNF $\alpha$ and IL-1 $\beta$ release was measured by ELISA following the manufacturer's instructions. Saline-treated, LPS-stimulated controls were also included for calculating \% inhibition of cytokine release. PLA 3.0 bioassay software (Stegmann Systems, Rodgau, Germany) was used to calculate relative potency as compared to similarly prepared LMWF5A reference material tested on each plate.

\section{HEK293 luciferase reporter assay}

HEK-Dual TNF $\alpha$ cells (Invivogen, San Diego, CA; catalog \#hkd-tnfa) were used to assess the ability of LMWF5A to inhibit NF- $\mathrm{kB}$. These cells contain a reporter construct that encodes a secreted luciferase gene (Lucia) under the control of a NF- $\kappa B$ inducible promoter. $130 \mu \mathrm{L}$ LMWF5A was added in triplicate to a 96-well plate. $70 \mu \mathrm{L}$ HEKDual TNF $\alpha$ cells in DMEM (Corning, Manassas, VA) supplemented with $10 \%$ heat-inactivated FBS, $10 \mathrm{U} / \mathrm{mL}$ pencillin- $100 \mu \mathrm{g} / \mathrm{mL}$ streptomycin, $100 \mu \mathrm{g} / \mathrm{ml}$ normocin (Invivogen), and $100 \mu \mathrm{g} / \mathrm{ml}$ zeocin (Invivogen) were then added for a final concentration of 50,000 cells/well, and the cells were incubated at $37{ }^{\circ} \mathrm{C}$ and $5 \% \mathrm{CO}_{2}$ for $24 \mathrm{~h}$. To induce luciferase expression, the cells were stimulated with $2 \mathrm{ng} / \mathrm{mL}$ TNFo (Invivogen) for an additional $24 \mathrm{~h}$ at $37{ }^{\circ} \mathrm{C}$ and $5 \% \mathrm{CO}_{2}$. The luciferase activity was quantitated by combining $20 \mu \mathrm{L}$ each cell supernatant and 100 $\mu \mathrm{L}$ QUANTI-Luc reagent (Invivogen) in a new, opaque 96-well plate and immediately measuring luminescence on a SpectraMax M5e and Flexstation 3 System (Molecular Devices, San Jose, CA).

\section{Data and statistical analysis}

Statistical analysis was performed using the Real Statistics Resource Pack Excel Add-in (http://www.real-stati stics.com/) unless otherwise stated. For cytokine arrays, one-tailed, one-sample t-tests (hypothetical value $=0$; $\alpha=0.05)$ were used to establish meaningful OD measurements above medium-control blanks and two-tailed, one-sample t-tests were used to test for the significance of combined fold changes (hypothetical value $=1$; $\alpha=0.05)$. For DNA-binding ELISAs, two-tailed, twosample unequal variance student tests were used for the representative ELISAs in Microsoft Excel (Microsoft Corporation, Redmond, WA) and Wilcoxon signedranked tests were used for non-parametric analysis of combined fold changes (hypothetical value $=1 ; \alpha=0.05$ ). For potency assays, relative potency was calculated using parallel-line analysis with ANOVA with pure separation and similarity of sample responses was established by f-tests for non-parallelism, non-linearity, and significance of response in PLA 3.0 (Stegmann Systems GmbH, Raiffeisenstr, Germany).

\section{Results \\ LMWF5A suppresses distinct pro-inflammatory cytokines in LPS-stimulated PBMC}

We have previously shown that LMWF5A exhibits antiinflammatory properties with an $\approx 35 \%$ inhibition of TNF $\alpha$ from LPS-induced human ex vivo PBMC cultures [22]. A 48-plex ELISA array of cytokines and chemokines was employed to assess broader effects in the same model. Consistent with historical findings, LMWF5A treatment resulted in a significant $(\mathrm{p} \leq 0.05) 38 \pm 6.7 \%$ inhibition or $0.62 \pm 0.07$-fold change in the measured OD signal for TNF $\alpha$ as compared to controls (Table 1). Also observed in conditioned media from LMWF5A-treated cells was significant suppression of CXCL9 $(0.48 \pm 0.01$ fold change), CXCL10 (0.36 \pm 0.15 -fold change), CXCL11

\section{Table 1 Pro-inflammatory cytokines and chemokines significantly suppressed by LMWF5A in LPS-stimulated PBMC}

\begin{tabular}{lll}
\hline Cytokine/chemokine & Gene symbol & Fold change \\
\hline C-X-C motif chemokine ligand 9 & CXCL9 & $0.48 \pm 0.01$ \\
C-X-C motif chemokine ligand 10 & CXCL10 & $0.36 \pm 0.15$ \\
C-X-C motif chemokine ligand 11 & CXCL11 & $0.58 \pm 0.08$ \\
Interleukin 1 beta & IL1 & $0.71 \pm 0.05$ \\
Interleukin 12 p40 and p70 & IL12A and B & $0.34 \pm 0.07$ \\
Tumor necrosis factor alpha & TNFA & $0.62 \pm 0.07$ \\
\hline
\end{tabular}

PBMC were exposed to saline or LMWF5A and then stimulated with $100 \mathrm{ng} /$ $\mathrm{ml}$ LPS for $24 \mathrm{~h}$. Cytokine release was determined by ELISA array, and data are presented as fold change (OD $\pm S T D, n=3, p$-value $=\leq 0.05)$ 
( $0.58 \pm 0.08$-fold change), IL- $1 \beta(0.71 \pm 0.05$-fold change $)$, and IL-12 (0.34 \pm 0.07 -fold change) (Table 1$)$. These findings demonstrate that in addition to TNF $\alpha$, LMWF5A treatment of LPS-stimulated PBMC results in a distinct cytokine signature, with reduced release of specific proinflammatory signals after $24 \mathrm{~h}$ in culture.

\section{Pathway enrichment analysis of LMWF5A differentially expressed gene sets identifies associations with CD4+Th1 inflammatory and $\mathrm{M} 1$ polarization markers}

Next, gene set enrichment analysis was used to gain mechanistic insight into the biologic processes underlying the identified differentially expressed cytokines by querying Enrichr using cytokine gene symbols [27, 28]. As expected for our LPS-stimulated PBMC model, the two most significant enrichment terms returned from the Wikipathways library involve LPS-related Toll-like receptor signaling pathways (Pathway\#s WP75 and WP1449) (Table 2). However, these are closely followed by overrepresentation in pathway terms for allograft rejection as the result of CD4+ T cell differentiation (Pathway\# WP2328), the differentiation or polarization of innate lymphoid progenitor cells (Pathway\# WP3893), and the AhR signaling pathway (Pathway\# WP2873) (Table 2). The top three pathways identified in the Biocarta library are associated with IL-2/IFN $\gamma / \mathrm{STAT}$-induced Th1 differentiation

Table 2 Enrichr gene enrichment analysis of the LMWF5A-reduced cytokine signature using Wikipathways, Biocarta, and Elsevier libraries

\begin{tabular}{|c|c|c|}
\hline Index & Name & P-value \\
\hline \multicolumn{3}{|c|}{ Wikipathways 2019 human } \\
\hline 1 & Toll-like Receptor Signaling Pathway WP75 & $7.81 \mathrm{E}-17$ \\
\hline 2 & Regulation of toll-like receptor signaling pathway WP1449 & $6.72 \mathrm{E}-16$ \\
\hline 3 & Allograft Rejection WP2328 & $4.56 \mathrm{E}-14$ \\
\hline 4 & Development and heterogeneity of the ILC family WP3893 & $1.88 \mathrm{E}-10$ \\
\hline 5 & Aryl Hydrocarbon Receptor Pathway WP2873 & $8.53 E-10$ \\
\hline 6 & Cytokines and Inflammatory Response WP530 & $6.80 \mathrm{E}-08$ \\
\hline 7 & Resistin as a regulator of inflammation WP4481 & $1.43 \mathrm{E}-07$ \\
\hline 8 & Fibrin Complement Receptor 3 Signaling Pathway WP4136 & 2.03E-07 \\
\hline 9 & Type II interferon signaling (IFNG) WP619 & 2.03E-07 \\
\hline 10 & Lung fibrosis WP3624 & $1.03 \mathrm{E}-06$ \\
\hline \multicolumn{3}{|c|}{ Biocarta 2016} \\
\hline 1 & NO2-dependent IL 12 Pathway in NK cells Homo sapiens h no2il12Pathway M6231 & $3.78 \mathrm{E}-06$ \\
\hline 2 & IL12 and Stat4 Dependent Signaling Pathway in Th1 Development Homo sapiens h IL12Pathway M4319 & $1.10 \mathrm{E}-05$ \\
\hline 3 & NFkB activation by Nontypeable Hemophilus influenzae Homo sapiens h nthiPathway M2821 & 4.24E-05 \\
\hline 4 & Signal transduction through IL1R Homo sapiens h il1 rPathway M12095 & $6.58 \mathrm{E}-05$ \\
\hline 5 & Visceral Fat Deposits and the Metabolic Syndrome Homo sapiens h vobesityPathway M22017 & $2.80 \mathrm{E}-03$ \\
\hline 6 & SODD/TNFR1 Signaling Pathway Homo sapiens h soddPathway M2699 & $3.15 \mathrm{E}-03$ \\
\hline 7 & IL-10 Anti-inflammatory Signaling Pathway Homo sapiens h il10Pathway M6778 & $4.54 \mathrm{E}-03$ \\
\hline 8 & Stress Induction of HSP Regulation Homo sapiens h hsp27Pathway M2587 & 4.89E-03 \\
\hline 9 & Cadmium induces DNA synthesis and proliferation in macrophages Homo sapiens h cdMacPathway M4388 & $5.59 \mathrm{E}-03$ \\
\hline 10 & TNFR1 Signaling Pathway Homo sapiens h tnfr1Pathway M3618 & $5.94 \mathrm{E}-03$ \\
\hline \multicolumn{3}{|c|}{ Elsevier } \\
\hline 1 & Macrophage M1 Lineage & $1.42 \mathrm{E}-15$ \\
\hline 2 & Proteins Involved in Psoriasis & $3.54 \mathrm{E}-15$ \\
\hline 3 & IL6/IL12 Signaling Activates Immune System in Multiple Sclerosis & $6.74 \mathrm{E}-15$ \\
\hline 4 & Toll-like Receptors in beta-Cell & $1.08 \mathrm{E}-12$ \\
\hline 5 & CCR1 Expression Targets & $9.19 \mathrm{E}-11$ \\
\hline 6 & Nociception Expression Targets Signaling & $3.62 \mathrm{E}-10$ \\
\hline 7 & Toll-like Receptors Act through MYD88-TIRAP Signaling & $5.29 \mathrm{E}-10$ \\
\hline 8 & Dendritic Cells Function in Psoriasis & $6.45 \mathrm{E}-10$ \\
\hline 9 & Dendritic Cell Function in Ulcerative Colitis & $8.53 E-10$ \\
\hline 10 & Hashimoto's Thyroiditis & $1.31 \mathrm{E}-09$ \\
\hline
\end{tabular}


(Systemic names M6231 and M4319) and the activation of NF-kB (Systemic name M2821) (Table 2). Interestingly, Biocarta also found significant overrepresentation in two well-known anti-inflammatory pathways: the PPAR $\gamma$-related obesity pathway (Systemic name M22017) and the IL-10/JAK/STAT signaling pathway that result in the repression of TNF $\alpha$, IL-1, and IL-6 (Systemic name M6778) (Table 2). Finally, when mined by literature in the Elsevier pathway collection, M1 macrophage polarization is associated with the LMWF5A gene set (Table 2). Together these findings suggest that the cytokine genes found to be influenced by LMWF5A treatment of LPSstimulated PBMC are linked to classical CD4+ Th1 T cell activation, M1 macrophage polarization phenotypes, and the modulation of pro- and anti-inflammatory pathways, including PPAR $\gamma$, AhR, NF- $\mathrm{kB}$, and STAT.

\section{Transcription factor enrichment analysis suggests that LMWF5A treatment involves changes in NF-kB and STAT activity}

To identify transcription factors that are potentially responsible for the LMWF5A-reduced cytokine signature, differentially abundant cytokines were input into Chea3 [29]. When sorted by mean rank, the most highly associated transcription factor predicted to regulate this set of cytokines is basic leucine zipper transcription factor ATF-like 3 (BATF3), which heterodimerizes with AP-1 to function as a transcriptional repressor and may play a role in the fate of T-cell differentiation [30] (Table 3). Importantly, pro-inflammatory NF- $\mathrm{BB}$ family member subunits (NFKB2 and REL) and STAT1 are also represented (Table 3). In support of the initial rankings, the NF-kB subunits RELA, NFKB2, and RELB as well as STAT1 are overrepresented when assembled by gross number of overlapping genes (Table 3 ). In addition, sorting by overlapping genes indicates that most of the genes submitted have upstream c-Jun AP-1 promoter elements (Table 3). Thus, these data imply that the cytokines that are reduced by LMWF5A in PBMCs are, in part, regulated by NF-kB, STAT, and AP-1.

\section{LMWF5A reduces transcription factor/DNA-binding activity}

The regulatory picture provided by enrichment analysis suggests that LMWF5A treatment of LPS-stimulated PBMC results in reduced Th1/M1 differentiation or activation through attenuation in the activity of hallmark pro-inflammatory TFs, such as AP-1, NF- $\mathrm{kB}$, and STAT. To test this hypothesis, nuclear protein extracts were collected from unstimulated and LPS-stimulated PBMC

Table 3 Chea3 transcription factor enrichment analysis of the LMWF5A-reduced cytokine signature

\begin{tabular}{|c|c|c|c|}
\hline Rank & Transcription factor & Mean rank & $\begin{array}{l}\text { Overlapping } \\
\text { genes }\end{array}$ \\
\hline \multicolumn{4}{|c|}{ Sorted by mean rank } \\
\hline 1 & Basic leucine zipper transcription factor, ATF-like 3 (BATF3) & 10.33 & 4 \\
\hline 2 & Nuclear factor of kappa light polypeptide gene enhancer in B-cells 2 (p49/p100) (NFKB2) & 17.25 & 5 \\
\hline 3 & Ets variant 3-like (ETV3L) & 17.33 & 3 \\
\hline 4 & Interferon regulatory factor 8 (IRF8) & 24 & 3 \\
\hline 5 & v-rel avian reticuloendotheliosis viral oncogene homolog (REL) & 25 & 3 \\
\hline 6 & Zinc finger protein 267 (ZNF267) & 32 & 3 \\
\hline 7 & Signal transducer and activator of transcription 1, 91 kDa (STAT1) & 33.83 & 5 \\
\hline 8 & Musculin (MSC) & 38 & 3 \\
\hline 9 & Basic leucine zipper transcription factor, ATF-like (BATF) & 38.2 & 5 \\
\hline 10 & Early growth response 2 (EGR2) & 40.33 & 3 \\
\hline \multicolumn{4}{|c|}{ Sorted by overlapping genes } \\
\hline 93 & v-rel avian reticuloendotheliosis viral oncogene homolog A (RELA) & 252.7 & 7 \\
\hline 409 & Jun proto-oncogene (JUN) & 530 & 5 \\
\hline 354 & Estrogen receptor 1 (ESR1) & 490.8 & 5 \\
\hline 2 & Nuclear factor of kappa light polypeptide gene enhancer in B-cells 2 (p49/p100) (NFKB2) & 17.75 & 5 \\
\hline 7 & Signal transducer and activator of transcription 1, 91 kDa (STAT1) & 34.67 & 5 \\
\hline 28 & Zinc finger, BED-type containing 2 (ZBED2) & 143.7 & 5 \\
\hline 67 & v-rel avian reticuloendotheliosis viral oncogene homolog B (RELB) & 215 & 5 \\
\hline 95 & Ets variant 7 (ETV7) & 257.3 & 5 \\
\hline 242 & SP140 nuclear body protein (SP140) & 412 & 5 \\
\hline 314 & Basic leucine zipper transcription factor, ATF-like 2 (BATF2) & 463.3 & 5 \\
\hline
\end{tabular}


cultured in the presence of saline or LMWF5A for $24 \mathrm{~h}$ and TF activation was assessed by specific DNA-binding ELISAs. Phosphorylated c-Jun antibody was chosen for ELISA quantification to represent AP-1 activation, but no changes in optical density (OD) were observed between diluent controls and LMWF5A treatment groups (data not shown). However, as presented in Fig. 1a and b, significant reductions in ELISA OD measurements for the canonical p65 and non-canonical RelB NF- $\mathrm{KB}$ subunits were observed in LPS-stimulated, LMWF5A-treated nuclear protein samples. In addition, STAT $1 \alpha$ and STAT3 DNA binding was reduced in the nuclear compartment in both unstimulated and LPS-stimulated PBMC following LMWF5A treatment (Fig. 1c and d).

To gauge the magnitude and repeatability of these responses, fold changes in OD between saline controls and LMWF5A treatments for 4-6 independent experiments were then compared to a hypothetical fold change of 1.0 for both unstimulated and LPS-stimulated cells. In addition, fold changes in the LPS-induced activation signal, adjusted to account for constituent DNA-binding activity, were also calculated by subtracting the unstimulated OD from total OD in LPS activation treatment groups. Due to the complex nature of TF DNA-binding activity and the fact that some of the investigated TFs appear to depend on activation-induced expression (i.e. RelB, Fig. 1b), both of which may impact distributions, non-parametric tests were used to test for significance. For p65, fold change in activity trends to be lower with LMWF5A treatment compared to the saline control in unstimulated cultures (Median $=0.87$, Interquartile Range $[\mathrm{IQR}]=0.79$ to $0.92, \mathrm{p}=0.14)$, LPS-stimulated cultures (Median $=0.78, \mathrm{IQR}=0.75$ to $0.85, \mathrm{p}=0.06$ ), and the LPS-induced activation signal (Median $=0.69$, $\mathrm{IQR}=0.62$ to $0.81, \mathrm{p}=0.10$ ) (Fig. $2 \mathrm{a}-\mathrm{c}$ ). Interestingly, RelB activity was not detected in unstimulated cells. As a result, fold change in unstimulated treatment groups could not be calculated and the LPS-induced activation signal is reflected in the stimulated fold change for this NF- $\mathrm{kB}$ subunit. The biologic implications of this observation suggest that RelB must be expressed following stimulation or that this subunit is highly sequestered in the cytoplasm, which could explain the broad distribution in LMWF5A-induced fold change observed (Median $=0.44$, $\mathrm{IQR}=0.26$ to $0.71, \mathrm{p}=0.20$, Fig. $2 \mathrm{~b}$ ). As for $\mathrm{STAT} 1 \alpha$, LMWF5A treatment results in a significant reduction in the OD measurement quantifying DNA binding in unstimulated cells (Median $=0.58, \mathrm{IQR}=0.47$ to 0.77 ,
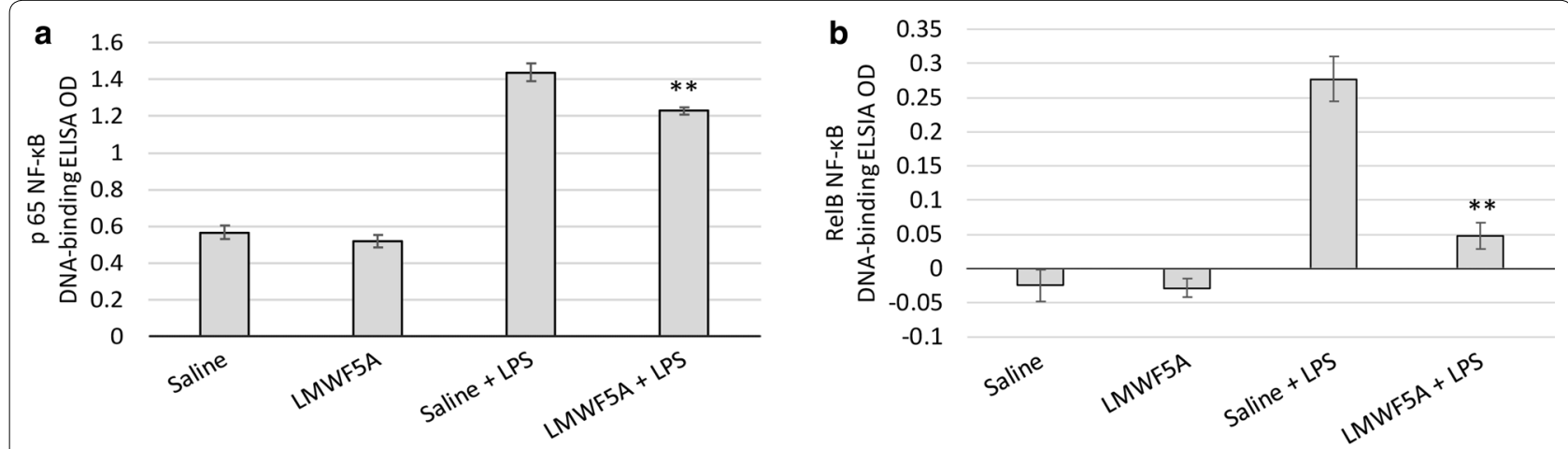

C

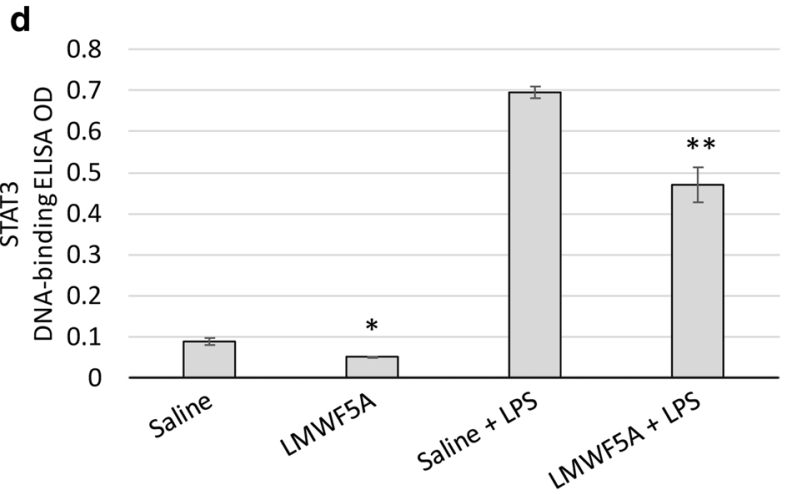

Fig. 1 Representative transcription factor/DNA-binding ELISA results. PBMC exposed to saline or LMWF5A were stimulated with $100 \mathrm{ng} / \mathrm{ml}$ LPS or left unstimulated. After $24 \mathrm{~h}$, nuclear protein was harvested and subjected to DNA-binding ELISAs for p65 NF-KB (a), RelB NF-KB (b), STAT1 a (c), and STAT3 $(\mathbf{d})$. Data are presented as OD $\pm \operatorname{STD}(n=3) .{ }^{*}$ indicates $p \leq 0.05$ versus unstimulated saline control, and ${ }^{* *}$ indicates $p \leq 0.05$ versus LPS-stimulated saline control 

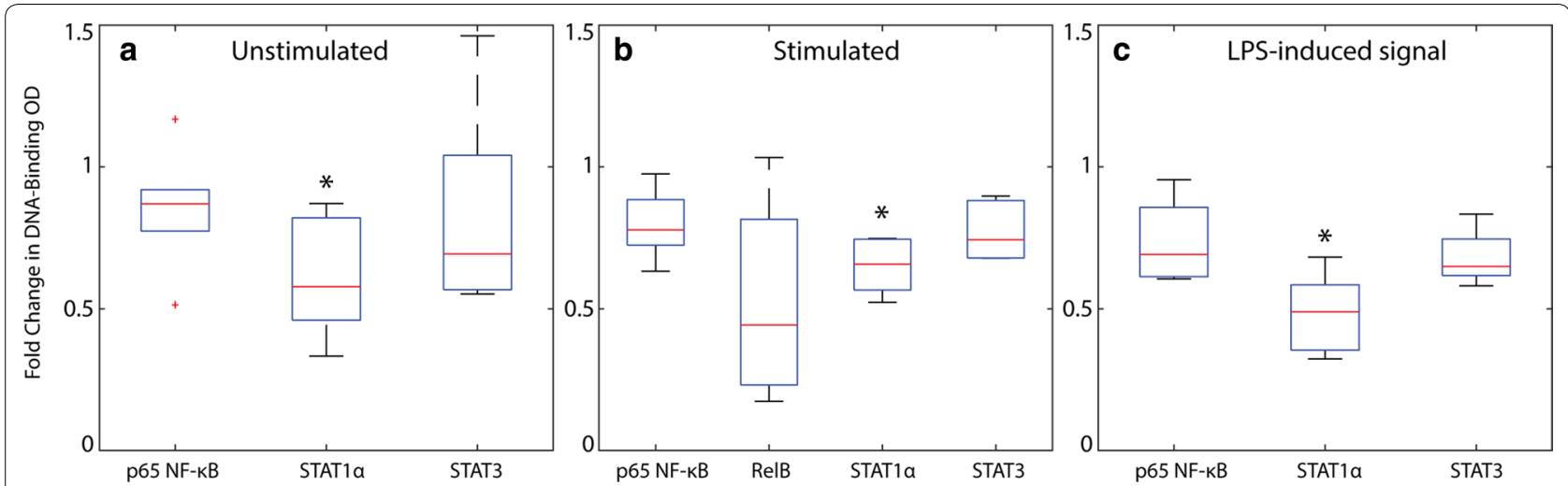

Fig. 2 Box plots of LMWF5A-induced fold changes in nuclear transcription factor/DNA binding. Nuclear protein extracts were collected from PBMC exposed to saline or LMWF5A and stimulated with $100 \mathrm{ng} / \mathrm{ml}$ LPS or diluent control for $24 \mathrm{~h}$. Transcription factor activity was then evaluated by DNA-binding ELISA, and fold changes in OD measurements were calculated for saline versus LMWF5A treatment groups for unstimulated nuclear protein samples (a), LPS-stimulated nuclear protein samples $(\mathbf{b})$ and LPS-induced activation signal with unstimulated OD subtracted (c). Data are presented as fold change in OD $\pm \mathrm{IQR}(n=4-6)$. red line = median fold change, and * indicates $p \leq 0.05$ versus hypothetical 1.0-fold change

$\mathrm{p}=0.036$ ), stimulated cells (Median $=0.66, \mathrm{IQR}=0.58$ to $0.73, \mathrm{p}=0.036)$, and the LPS-induced activation signal (Median $=0.49, \mathrm{IQR}=0.38$ to $0.57, \mathrm{p}=0.036$ ) (Fig. 2a-c). When STAT3 activity was evaluated, no significant change was observed in unstimulated cells (Median $=0.69$, IQR $=0.57$ to $0.90, p=0.59$ ) while stimulated cells (Median $=0.74, \mathrm{IQR}=0.68$ to $0.88, \mathrm{p}=0.059$ ) and the LPS-induced activation signal (Median $=0.65$, $\mathrm{IQR}=0.63$ to $0.72, \mathrm{p}=0.059)$ trends to exhibit reduced DNA-binding in LMWF5A treatment groups (Fig. 2a-c). These findings suggest that LMWF5A reduces STAT1 $\alpha$ activity, as measured by protein binding to specific DNA motifs, $24 \mathrm{~h}$ after treatment. Furthermore, LMWF5A may also reduce, to a lesser degree, the detectable DNAbinding activity of STAT3 as well as p65 and RelB NF- $\mathrm{kB}$ family members subunits, that may prove non-parametrically significant with more replication.

\section{LMWF5A reduces NF-KB luciferase reporter activity}

NF- $\mathrm{kB}$ signaling is the culmination of hetero- and homodimers, consisting of five family member TFs, that can form a least 12 distinct combinations [31]. To address these complexities and capture the broader impact of LMWF5A on NF- $\mathrm{kB}$ signaling, a luciferase reporter system was employed. Because PBMC present technical difficulties for this model, a stably transfected NF- $\mathrm{KB}$ promoter-driven HEK293 reporter line (Invivogen HEKDual TNF $\alpha$ ) was purchased and grown under selection conditions. The stably transfected construct consists of Lucia luciferase under the control of an IFN- $\beta$ minimal promoter fused to five copies of the NF- $\mathrm{KB}$ consensus translational response element and three copies of the c-Rel binding site. HEK-Dual TNF $\alpha$ cells were cultured for $24 \mathrm{~h}$ with saline or serially diluted LMWF5A, and luciferase expression was evaluated $2 \mathrm{~h}$ after stimulation. Because HEK293 cells do not express innate patternrecognition machinery in a similar fashion to PBMC, these cells were alternatively stimulated with $2 \mathrm{ng} / \mathrm{ml}$ $\mathrm{TNF} \alpha$, instead of LPS, to trigger robust signaling and activation. LMWF5A treatment resulted in the dosedependent inhibition of TNF $\alpha$-induced luciferase expression, ranging from $46 \pm 1.2 \%$ to $21 \pm 3.8 \%$, as compared to saline-treated, TNF $\alpha$-stimulated controls $\left(R^{2}=0.98\right.$, Fig. 3). These percent inhibition findings represent a change in the absolute luciferase luminescence units of 36,000 to 51,000 (Additional file 1: Fig. S1). When applying drug without saline dilution, LMWF5A was found to

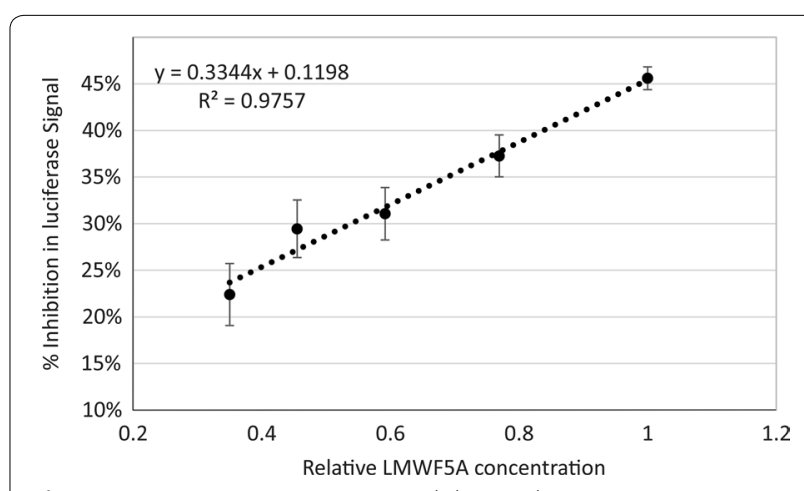

Fig. 3 Representative LMWF5A \% inhibition dose response in NF-KB reporter luciferase activity. HEK293 NF-KB luciferase reporter cells were treated with saline or serial dilutions of LMWF5A for $24 \mathrm{~h}$ and then stimulated with $2 \mathrm{ng} / \mathrm{ml}$ TNFa for $2 \mathrm{~h}$. Luciferase expression and release into the culture medium was then determined by luminescence. Data are presented as \% inhibition of luciferase activity for LMWF5A-treated, TNFa-stimulated cells versus saline-treated, TNFa-stimulated controls 
significantly inhibit reporter expression by $42 \pm 6 \%$ across a total of 21 replicates (data not shown). This observation suggests that while LMWF5A does not significantly reduce $\mathrm{p} 65$ and RelB DNA binding, treatment effects the functional NF-kB-driven expression of luciferase.

\section{PPARY and AhR antagonists reduce LMWF5A drug potency}

Based on bioinformatic analysis and historical findings, we hypothesize that the biologic mechanisms surrounding LMWF5A's anti-inflammatory activity involve activation of immunoregulatory signaling pathways and ligand-activated TFs. Our group previously reported that LMWF5A-induced AhR activation is involved in the inhibition of IL-6 release from LPS-stimulated, macrophage-like THP-1 cells [24]. In support of this, the AhR immunoregulatory pathway was identified by gene enrichment analysis in the current study using our PBMC model. Furthermore, it has been established that sodium caprylate, one of the identified active components found in LMWF5A [22], can serve as an agonist for PPAR $\gamma$ [32]. Importantly, a large body of evidence demonstrates that these pathways can regulate the activity of pro-inflammatory TFs as well as drive differentiation of immune cell subsets [33-35]. In addition, studies suggest that HEK293 cell lines express and are influenced by AhR and PPARY [36, 37]. Consequently, activation of these pathways may contribute to the ability of LMWF5A to suppress the release of pro-inflammatory cytokines from activated immune cells.

Relative potency (REP) was chosen as a robust metric for examination of our hypotheses. To establish overall drug activity, a relative potency assay was developed and validated, in adherence to USP 1032, 1033, and 1034 guidelines, based on the ability of LMWF5A to inhibit TNF $\alpha$ release in our established PBMC model. In brief, PBMC were stimulated overnight with LPS in the presence of 1.4-fold serial dilutions of LMWF5A and then TNF $\alpha$ release into the medium was determined by ELISA. Following this dilution scheme, LMWF5Ainduced TNF $\alpha$ inhibition exhibits a log-linear dose response conducive to parallel-line REP calculation. Thus, separation in parallel responses can then be used to calculate the biologic activity of tested samples in relation to reference materials. Horizontal shifts in transformed TNF $\alpha$ inhibition dose response curves are observed when testing LMWF5A samples of known activity using this model (Additional file 2: Fig. S2A-C). Intermediate precision regression analysis, which assesses the accuracy and closeness of analytical samples, shows a correlation of 0.987 between expected and measured REP of reference LMWF5A samples manipulated into having differing activities (Additional file 2: Fig. S2D). These data demonstrate that this method provides a highly accurate and precise bioassay for determining changes in LMWF5A drug potency.

The involvement of suspected pathways in the biologic activity of LMWF5A was then evaluated via this bioassay using specific antagonists for both PPARY (GW9662, MilliporeSigma) and AhR (CH223191, MilliporeSigma). Exposure of PBMC to $0.5 \mu \mathrm{M}$ and $0.05 \mu \mathrm{M}$ final concentrations of GW9662 and CH223191 respectively, resulted in shifts towards reduced potency in the log-linear dose response for LMWF5A-induced TNF $\alpha$ inhibition (Fig. 4a and b). Additionally, IL- $1 \beta$ release exhibited a similar loglinear dose response in this serial dilution range, and as a result, relative potency for IL- $1 \beta$ was calculated. As with TNF $\alpha$, PPAR $\gamma$ and AhR antagonism resulted in linear shifts in IL-1 $\beta$ dose responses that reflect a loss of drug potency (Fig. 4c and d). REP calculated for 3 independent experiments resulted in the reduction of mean REP to $0.74 \pm 0.05$ and $0.63 \pm 0.14$ for TNF $\alpha$ and IL- $1 \beta$, respectively, when cells were treated with GW9662 in concert with LMWF5A (Table 4). Treatment with CH223191 also resulted in significant reduction in TNF $\alpha$ and IL-1 $\beta$ $\%$ inhibition potency to mean REP of $0.76 \pm 0.09$ and $0.72 \pm 0.09$, respectively. Collectively, these findings show that chemical antagonism of PPAR $\gamma$ and AhR transcription factors interfered with the overall anti-inflammatory activity of LMWF5A.

\section{Discussion}

This investigation demonstrates that the therapeutic potential of LMWF5A involves activation of AhR and PPAR $\gamma$ immunoresolvent signaling pathways. Specifically, we report that specific antagonists for these TFs block the anti-inflammatory activity of LMWF5A as measured by suppression of TNF $\alpha$ and IL- $1 \beta$ release from LPS-stimulated PBMC. Here for the first time, we also present evidence that LMWF5A functions by inhibiting STAT $1 \alpha$ DNA-binding activity as well as potentially trans-repressing overall NF-kB-driven expression. Hence, we propose that modulation of these pathways provides a pharmacological tool for manipulating the progression of immune responses and may contribute to the observed clinical efficacy of LMWF5A.

One of the primary findings in our study is that the AhR antagonist CH223191 attenuates LMWF5A drug potency as measured by the inhibition of both TNF $\alpha$ and IL- $1 \beta$ release. This is in agreement with a previous study in which $\mathrm{CH} 223191$ partially blocks LMWF5A-induced inhibition of IL-6 from macrophage-like LPS-stimulated, PMA-differentiated THP-1 cells [24]. To put this in context, the most abundant molecule found in LMWF5A is $\mathrm{N}$-acetyl-tryptophan (NAT). This synthetic amino acid is added to pharmaceutical $5 \%$ human serum albumin, the starting material for LMWF5A, at high concentration 

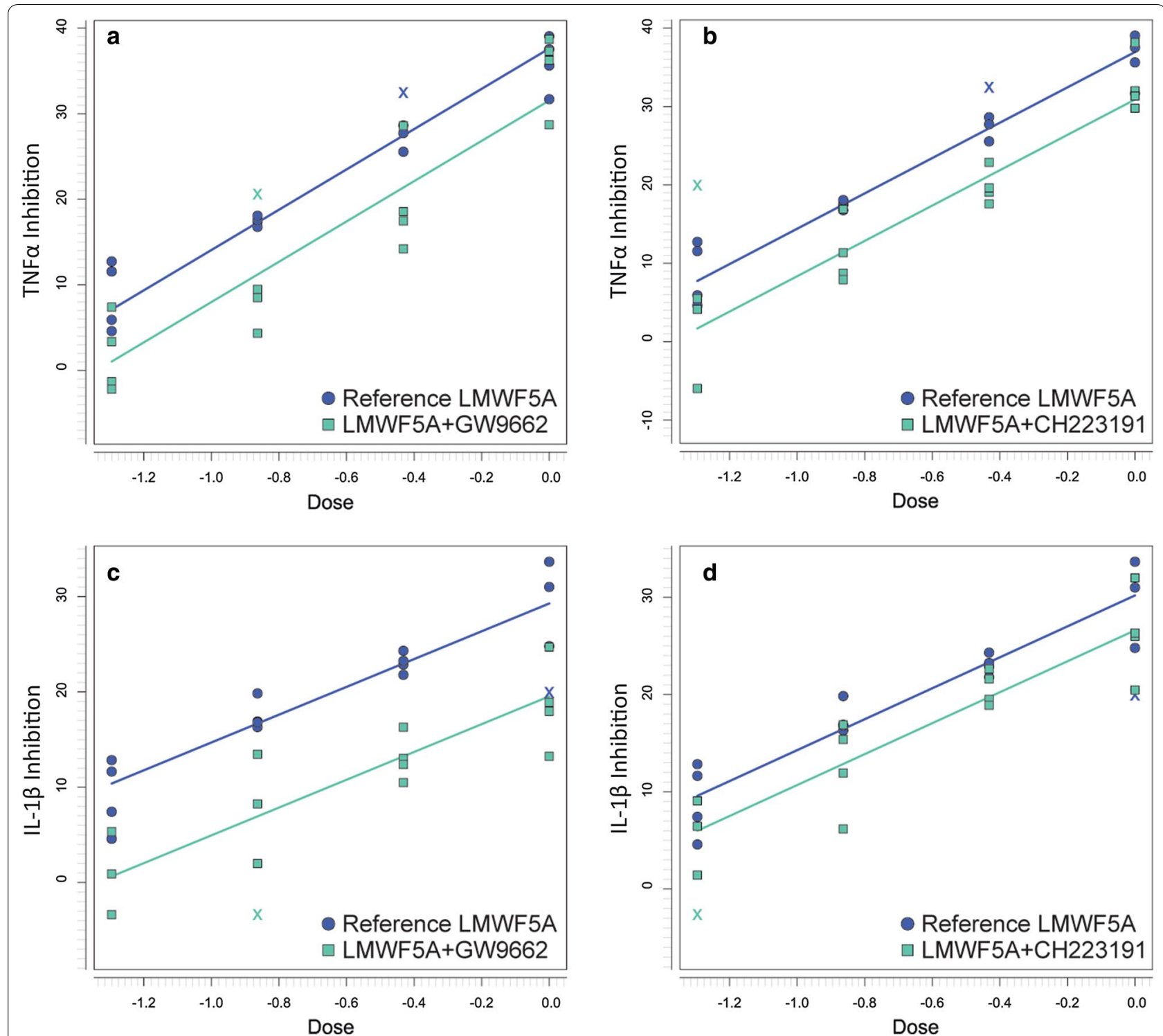

Fig. 4 Representative TNFa and IL-1 $\beta$ \% inhibition REP bioassays for antagonist-treated reference drug material. Dose responses in \% inhibition TNFa release ( $\mathbf{a}$ and $\mathbf{b}$ ) or IL-1 $\beta$ release ( $\mathbf{c}$ and $\mathbf{d}$ ) for diluent control-treated reference LMWF5A and $0.5 \mu \mathrm{M}$ GW9662 PPARY antagonist-treated reference LMWF5A (a and c) or $0.05 \mu \mathrm{M} \mathrm{CH} 223191$ AhR antagonist-treated reference LMWF5A (b and $\mathbf{d}$ ). Blue = Reference drug material dose response, Green $=$ Antagonist-treated reference drug material dose response

Table 4 Effect of GW9662 or CH223191 antagonism on LMWF5A drug potency

\begin{tabular}{llllll}
\hline Antagonist (pathway) & Cytokine & Mean REP \pm STD $(\mathbf{9 5} \%$ Cl) & REP 1 (95\% Cl) & REP 2 (95\% CI) & REP 3 (95\% CI) \\
\hline GW9662 (PPAR) & TNFa & $0.74 \pm 0.05(0.69-0.80)$ & $0.77(0.67-0.88)$ & $0.69(0.63-0.75)$ & $0.77(0.68-0.88)$ \\
& IL-1 $\beta$ & $0.63 \pm 0.14(0.48-0.80)$ & $0.51(0.40-0.63)$ & $0.61(0.48-0.74)$ & $0.79(0.69-0.90)$ \\
CH223191 (AhR) & TNFa & $0.76 \pm 0.09(0.67-0.86)$ & $0.68(0.57-0.78)$ & $0.85(0.77-0.93)$ & $0.76(0.67-0.86)$ \\
& IL-1 $\beta$ & $0.72 \pm 0.09(0.62-0.82)$ & $0.80(0.67-0.94)$ & $0.74(0.58-0.82)$ & $0.62(0.53-0.70)$ \\
\hline
\end{tabular}

Data are presented as mean $\mathrm{REP} \pm \mathrm{STD}$ and $95 \% \mathrm{Cl}$ of three independent experiments 
( $4 \mathrm{mM}$ ) to help stabilize the protein, with the added benefit of serving as a reactive oxygen species scavenger [38]. Subsequent oxidative breakdown of NAT results in the production of a variety of tryptophan-like metabolites, which have been identified in both HSA solutions as well as LMWF5A [24, 38]. It is also well established that enzymatic catabolism of tryptophan by indoleamine 2,3-dioxygenase (IDO) results in production of biologically active metabolites that act via AhR [11]. These data lead us to believe that NAT metabolism contributes to the biologically relevant activation of AhR by LMWF5A.

AhR is a ligand-activated member of the basic helixloop-helix TF family. The latent form of AhR resides in the cytosol, complexed together with two heat shock protein $90 \mathrm{~s}$, XAP-molecule 2, the co-chaperone p23, and potentially Src tyrosine kinase, which protects AhR from proteasomal degradation [11]. Ligand docking results in translocation of the complex to the nucleus, where AhR heterodimerizes with Ah receptor nuclear translocator (ARNT) [39]. Together, the AhR/ARNT complex provides a functional DNA-binding domain for a specific motif known as the dioxin or xenobiotic-response element (XRE) that influences the transcription of a diverse set of genes, including the xenobiotic metabolizing enzyme cytochrome $\mathrm{P} 450$ family-1 subfamily-A polypeptide-1 [40]. Interestingly, preliminary RNA-sequencing experiments, performed on a variety of cell types, identify cytochrome p 450 genes as some of the most highly LMWF5A-regulated genes, suggesting that this pathway is indeed activated by treatment (unpublished findings).

It is now recognized that in addition to its classical transcriptional activity, AhR can repress and/or alter NF- $\mathrm{B}$ activity through the formation of unique complexes that act as cofactors or cis-acting elements. NF- $k B$ is a family of five structurally similar members, including p65 or RelA, p50, p52, c-Rel, and RelB, which can target gene expression following inflammatory activation in various homo- and hetero- dimer combinations [7]. In some studies, AhR signaling skews the combinatorial makeup of NF- $\mathrm{kB}$ dimers that enter the nucleus and physically bind to cognate DNA sequences. For instance, Puga et al. demonstrated that AhR ligand treatment of mouse cell lines results in enhanced formation of repressive p50/p50 NF- $\mathrm{kB}$ homodimers, which may result in a competitive reduction in inflammatory p50/RelA NF- $\mathrm{kB}$ heterodimer formation and binding [41]. However, this response appears to be cell type- and ligand-dependent. For example, in dendritic cells it has been observed that AhR activation inhibits overall RelA DNA binding with no apparent change in the complexing of p50, suggesting that AhR-driven NF- $\mathrm{kB}$ suppression can also result from of sequestering of specific subunits in the cytosol [42]. Interestingly, the possibility also exists that concomitant activation of NF- $\mathrm{kB}$ and AhR results in the generation of alternate immunoregulatory pathways. Several lines of evidence suggest that complexes containing AhR and RelB or RelA can serve as functional dimers that mediate the expression of pro-inflammatory cytokines or inhibit gene expression driven by XREs [43, 44]. Finally, AhR can also impact the activity of NF- $\mathrm{kB}$ through direct trans-repression in the presence of STAT. This was exemplified in a study showing that ligand activated AhR complexes with STAT1 to physically suppresses NF-kB activity in LPS-activated peritoneal macrophages [45]. While these interactions still need to be fully elucidated, AhR activation appears to provide multiple avenues of transcriptional modulation that may explain the ability of LMWF5A to inhibit NF- $\mathrm{kB}$ activity and sequester STAT $1 \alpha$.

Extensive research chronicles the ability of AhR signaling to play a pivotal role in immunoregulation. Of note, most immune cells express AhR, which appears to increase in expression both during differentiation and upon exposure to pro-inflammatory conditions, and many inflammatory response-related genes contain upstream XREs [46]. Studies designed to evaluate the functional implications of AhR signaling on adaptive immunity reveal that activation promotes development of immunosuppressive Treg phenotypes [46]. However, AhR also conveys activity in innate immune responses. For example, LPS-induced production of IL-6, TNF $\alpha$, and $\mathrm{IL}-12$ is elevated from $\mathrm{AhR}^{-/-}$peritoneal macrophages as compared to wild-type controls [47]. Animal models also demonstrate the importance of AhR to the overall immune response. AhR-deficient mice exhibit lower IL-10 levels and augmented levels of IL-12 and IFNY following T-cell receptor activation or microbial challenge [46]. Moreover, the tryptophan-metabolizing enzyme IDO1 and the tryptophan metabolite kynurenine, together with the anti-inflammatory cytokine TGF $\beta$, are required for the development of endotoxin tolerance in murine models [48]. Taken together, these studies have established that AhR signaling is a fundamental part of immune suppression and end-stage resolution, providing an interesting therapeutic target for immunomodulation.

Another pivotal observation presented in this report is that PPARY antagonism with GW9662 also partially blocks LMWF5A-induced cytokine effects. As previously noted, indirect relationships between LMWF5A and PPARY signaling have been established in previous investigations. The first indication that this pathway is activated by LMWF5A was provided when sodium caprylate was identified an active component [22] because medium chain fatty acids, including caprylate, can serve as a PPAR $\gamma$ agonist [32]. Moreover, subsequent studies have shown that release of known endogenous lipid mediator 
ligands of PPAR $\gamma$, such as PGD2 and 15d-PGJ2, are potentiated by LMWF5A in PBMC [23]. Activation of this pathway by LMWF5A was further substantiated in a published study demonstrating that treatment of bone marrow-derived mesenchymal stem cells results in approximately four-fold increases in the DNA-binding activity of PPAR $\gamma$ and its binding partner, retinoid $X$ receptor as measured by hybridization in nuclear extracts [25]. Together, these data suggest that PPAR $\gamma$ signaling is involved in the biologic activity of LMWF5A; however, here for the first time, we provide direct evidence that this pathway is indeed crucial to the biologic activity of LMWF5A.

PPARs comprise a family of nuclear hormone receptors that are structurally similar to steroid receptors and regulate transcription through a diverse set of mechanisms $[14,34,49]$. In their classical mechanism, this family responds to the presence or absence of signal or ligand by inducing or repressing, respectively, transcription of a multitude of gene targets associated with fatty acid oxidation and metabolism [14, 34, 49]. In the absence of ligand, PPAR resides in the nucleus complexed with co-repressors to repress the expression of genes via a mechanism termed ligand-independent trans-repression [14, 34, 49]. Ligand binding-in the case of LMWF5A, possibly caprylate or $15 \mathrm{~d}-\mathrm{PGJ} 2$ recognition-leads to ligand-dependent trans-activation, which commences with conformational changes that cause disassociation from co-repressors and allow for heterodimerization to its PPAR response element binding partner, the retinoid $X$ receptor [14]. In addition, PPARs can evoke anti-inflammatory outcomes through ligand-dependent trans-repression in several distinct fashions. For example, PPARs have been demonstrated to directly interact with the p65 and p50 subunits of NF-kB as well as the c-Jun subunit of AP-1, preventing their ability to bind to their DNA response elements [50, 51]. Moreover, PPAR can also reduce NF- $\mathrm{kB}$ and AP-1 activity by modulating expression and activity of key upstream proteins and enzymes, such as inhibitor of nuclear factor kappa B, c-Jun N-terminal kinase, and p38 mitogen-activated protein kinase [14]. Studies of PPAR agonists have also demonstrated the functional outcome of these activities, as they antagonize AP-1, STAT, and NF-kB in LPS-stimulated macrophages [52]. Thus, via trans-repression, PPAR activation may suppress pro-inflammatory TF activity and production of key inflammatory cytokines, including TNF $\alpha$, IL-12, and IL-1 $\beta$.

PPARs are widely known as drug targets for diabetes due to their inherent regulation of genes related to glucose metabolism and fatty acid storage, but have more recently become prominent for their anti-inflammatory activity [49]. Several studies have shown that the PPARY agonists, such 15d-PGJ2, ciglitazone, and pioglitazone, confer protection in neuroinflammatory and sepsis animal models through the inhibition of STAT, AP-1, and NF- $\mathrm{kB}$ activity as well as reduced Th1 differentiation [5355]. Furthermore, one of the hallmarks of the transition into immune resolution is the class-switching of eicosanoids to PGD2 and 15d-PGJ2 isoforms [49]. In support of this aspect of PPARy biology, agonists appear to attenuate inflammatory pain responses and promote tissue repair by driving the conversion of macrophages to the M2 phenotype [56, 57]. It has also been well documented that PPARy ligands negatively regulate the production of pro-inflammatory cytokines, such as TNF $\alpha$, IL-1 $\beta$, IL-2, IFN $\gamma$, and CXCL10, from a diverse set of immune cells, including macrophages, dendritic cells, and $\mathrm{T}$ cells in cell culture [14]. Conversely, the Th2 cytokine IL-4 appears to mediate its anti-inflammatory activities by upregulating PPAR $\gamma$ expression, and full-blown inflammation requires down-regulation of PPAR $[58,59]$. Therefore, PPAR $\gamma$ is another intriguing target for treating inflammatory conditions.

There are several limitations of this investigation that should be noted. An important caveat for the interpretation of this study is the use of a single donor of PBMC cells exhibiting strong drug response. Previously we have demonstrated that in a similar model, LMWF5A exhibits the ability to inhibit LPS-induced TNF $\alpha$ release from a diverse set of PBMC donor lots by $26-46 \%$ [22]. While our prior data suggest that LMWF5A affects a broad range of genotypes, future work should explore if the findings presented in this report influence the donor-todonor variance observed in these models. In addition, the cytokine array utilized resulted in the identification of a limited number of inflammatory-associated protein markers for enrichment analysis. While this may result in a potentially biased set of genes, already linked to proinflammatory TFs, the resulting hypotheses generated were subject to subsequent confirmation by molecular means.

\section{Conclusion}

In conclusion, this study expands our knowledge on the mechanisms of action of LMWF5A. We have previously documented that LMWF5A can modulate both the activity of small GTPases, such as RAP-1, Rac-1, and RhoA, as well as alter cytoskeletal post-translational modifications and cellular arrangements $[25,60,61]$. These activities are attributed to the ability of LMWF5A reduce both adaptive immune cytokine release and endothelial permeability $[60,61]$. The findings presented in the current study provide new evidence on the mechanisms of action of LMWF5A, specifically that AhR and PPAR $\gamma$ signaling pathways are directly involved in LMWF5A-induced 


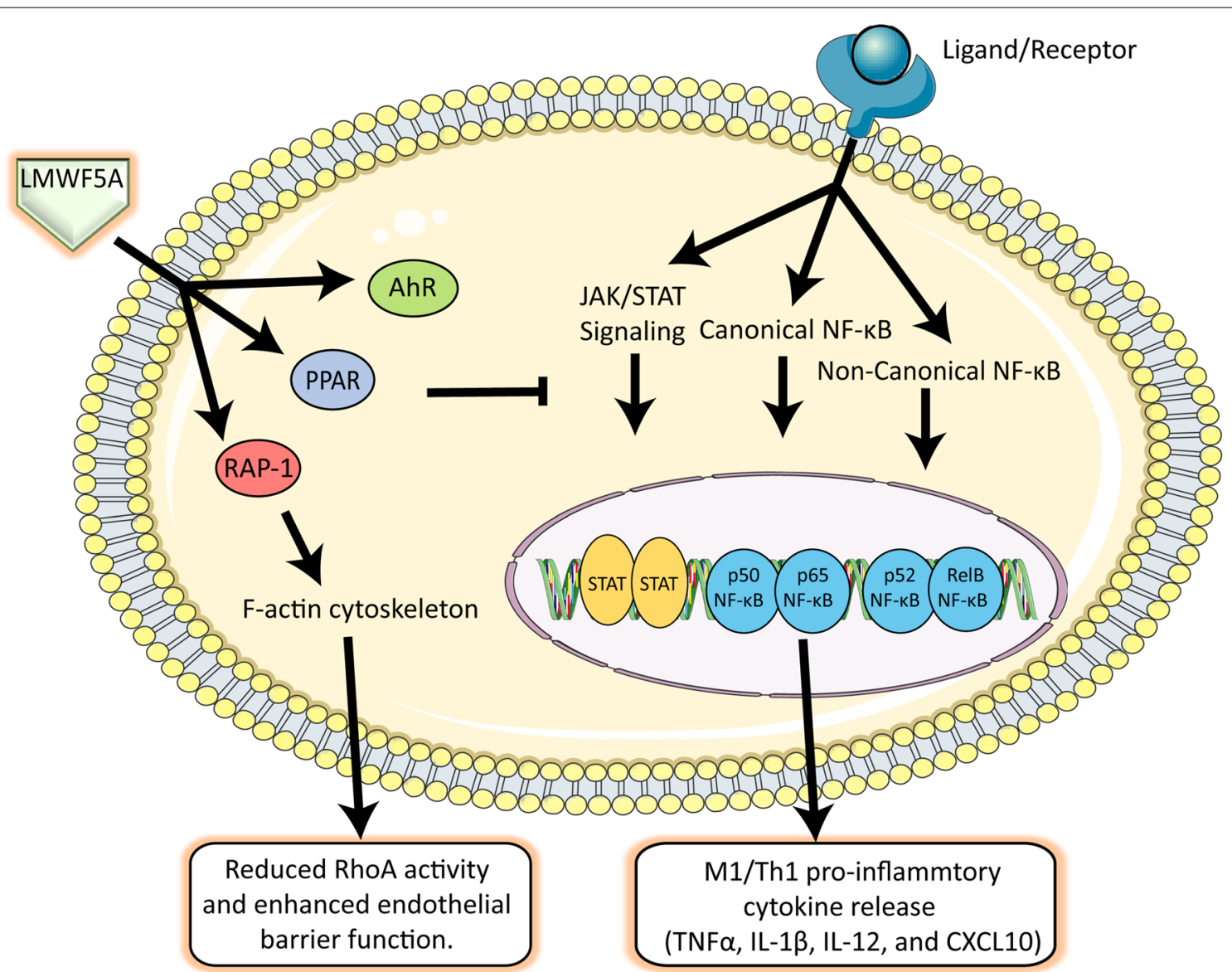

Fig. 5 LMWF5A mechanisms of action. The activation of JAK/STAT as well as both canonical and non-canonical NF-KB signaling pathways leads to the secretion of inflammatory M1 and Th1 cytokines associated with inflammatory disease and tissue damage. Treatment with LMWF5A results in the activation of PPARY and AhR, which may repress STAT and NF-KB transcriptional activity. In addition, LMWF5A activates RAP-1 small GTPase, which aids in reducing RhoA GTPase activity and promotes f-actin cytoskeletal rearrangements that enhance endothelial barrier function. Together, these mechanisms of actions may reduce leukocyte extravasation and impede M1 polarization to restore hemostasis in chronic settings

suppression of cytokine release in LPS-stimulated PBMC. Importantly, the distinct shift in M1/Th2 proinflammatory cytokine programming seen following LPS stimulation in this model suggests that LMWF5A is not simply acting as an anti-inflammatory, but in a polypharmacologic manner by exerting pro-resolving activities. Together, the known mechanisms of actions of LMWF5A may reduce leukocyte extravasation and impede M1 polarization to restore hemostasis in dysregulated inflammatory settings (Fig. 5). Exploiting these pathways and mechanisms with LMWF5A may hold promise not only in the treatment of osteoarthritis, but also in the treatment of a variety of inflammatory conditions as far ranging as the cytokine release syndromes seen in respiratory infections, inflammatory bowel disease, and central nervous system inflammation. These data provide previously undescribed mechanistic insight into the biologic activities of LMWF5A and should drive the informed repositioning of this novel biologic drug for the treatment of other inflammatory conditions.

\section{Supplementary information}

Supplementary information accompanies this paper at https://doi. org/10.1186/s12967-020-02626-z.

Additional file 1: Fig. 1. Representative LMWF5A dose response in NF-KB reporter luciferase activity. HEK293 NF-kB luciferase reporter cells were treated with serial dilutions of LMWF5A for $24 \mathrm{~h}$ and then stimulated with $2 \mathrm{ng} / \mathrm{ml}$ TNFa for $2 \mathrm{~h}$. Luciferase expression and release into the culture medium was then determined by luminescence. Data are presented as luciferase luminescence units.

Additional file 2: Fig. 2. Intermediate precision of TNFa REP bioassay. A-C) Representative transformed \% inhibition LPS-induced TNFa release versus nominal drug concentration for reference drug material (blue) versus test material (green) for 50\% (0.50) drug sample (A), 100\% (1.00) drug sample (B), and 200\% (2.00) drug sample (C). D) Regression analysis of measured REP versus theoretical REP intermediate precision $(n=5$ for $0.5 ; n=6$ for $0.75,1.00,1.50$, and 2.00 ). 


\section{Abbreviations}

LMWF5A: Low molecular weight fraction of human serum albumin; M1: Classically activated macrophage; M2: Alternatively activated macrophage; Th1: CD4+T helper $1 \mathrm{~T}$ cell; Th17: CD4+Thelper 17 T cell; Th2: CD4+T helper $2 \mathrm{~T}$ cell; TF: Transcription factor; NF-kB: Nuclear factor kappa-light-chain-enhancer of activated B cells; p50: NF-kB subunit p50; RelA: NF-kB subunit p65; RelB: NF-kB subunit RelB; p52: NF-kB subunit p52; c-Rel: NF-kB subunit c-Rel; NFKB2: NF-kB subunit p100; STAT: Signal transducer and activator of transcription; AhR: Aryl hydrocarbon receptor; PPAR: Peroxisome proliferator-activated receptor; AP-1: Activator protein; LPS: Lipopolysaccharide; PBMC: Peripheral blood mononuclear cells; PMA: Phorbol 12-myristate 13-acetate; TNFa: Tumor necrosis factor alpha; IFNY: Interferon gamma; IL-1 $\beta$ : Interleukin 1 beta; IL-2: Interleukin 2; IL-6: Interleukin 6; IL-10: Interleukin 10; IL-12: Interleukin 12; CXCL9: C-X-C motif chemokine ligand 9; CXCL10: C-X-C motif chemokine ligand 10; CXCL11: C-X-C motif chemokine ligand 11; OD: Optical density; IQR: Interquartile Range; JAK: Janus tyrosine kinase; BATF3: Basic leucine zipper transcription factor ATF-like 3; c-Jun: AP-1 protein c-Jun gene; REP: Relative potency; NAT: N-acetyl-tryptophan; IDO: Indoleamine 2,3-dioxygenase; ARNT: Ah receptor nuclear translocator; XRE: Xenobiotic-response element; TGF $\beta$ : Transforming growth factor beta; COX-2: Prostaglandin-endoperoxide synthase 2; PGE2: Prostaglandin $\mathrm{E}_{2} ;$ PGD2: Prostaglandin $\mathrm{D}_{2} ; 15 \mathrm{~d}$-PGJ2: 15-Deoxy$\triangle$-12,14-Prostaglandin $\mathrm{J}_{2}$; GTPase: Guanosine triphosphate hydrolase; RAP-1: Ras-related protein RAP-1; RhoA: Ras homolog family member A; Rac1: Rac family small GTPase 1.

\section{Acknowledgements}

Not applicable.

\section{Author contributions}

$\mathrm{GT}, \mathrm{EF}$, and RB-O: conception, implementation, and draft of manuscript. $\mathrm{MH}$ and LT: conception, implementation, and critical review of manuscript. YM, $\mathrm{CM}, \mathrm{MR}$, and DB-O: conception and critical review of manuscript. All authors read and approved the final manuscript.

\section{Funding}

This research did not receive any specific grant funding.

\section{Availability of data and materials}

The data analyzed during in this report are included in published articles or available from the corresponding author on reasonable request.

\section{Ethics approval and consent to participate}

Not applicable. All experiments referred to in this report were conducted with commercially available cell lines and/or primary human cells with all appropriate consents available from the suppliers.

\section{Consent for publication}

Not applicable.

\section{Competing interests}

G.T and R.B-O are employees, shareholders, and have been granted stock options at Ampio Pharmaceuticals. E.F., L.T., and Y.M are employees and have been granted stock options at Ampio Pharmaceuticals. M.H. is a shareholder of Ampio Pharmaceuticals stock. D.B-O is a Director and shareholder at Ampio Pharmaceuticals. All other authors have nothing to declare.

\section{Author details}

${ }^{1}$ Ampio Pharmaceuticals Inc, 373 Inverness Parkway Suite 200, Englewood, CO 80122, USA. ${ }^{2}$ Trauma Research Department, Swedish Medical Center, 501 E. Hampden Ave. Rm 4-454, Englewood, CO 80113, USA. ${ }^{3}$ Trauma Research Department, St. Anthony Hospital, 11600 W 2nd PI, Lakewood, CO 80228 , USA. ${ }^{4}$ Trauma Research Department, Penrose Hospital, 2222 N Nevada Ave, Colorado Springs, CO 80907, USA. ${ }^{5}$ Centura Health Systems, 9100 E. Mineral Cir, Centennial, CO 80112, USA. ${ }^{6}$ Department of Molecular Biology, Rocky Vista University, 8401 S Chambers Rd, Parker, CO 80134, USA.

Received: 17 September 2020 Accepted: 19 November 2020 Published online: 30 November 2020

\section{References}

1. Chen L, Deng H, Cui H, Fang J, Zuo Z, Deng J, et al. Inflammatory responses and inflammation-associated diseases in organs. Oncotarget. 2018;9:7204-18.

2. Sugimoto MA, Sousa LP, Pinho V, Perretti M, Teixeira MM. Resolution of inflammation: what controls its onset? Front Immunol. 2016;7:160.

3. Fang P, Li X, Dai J, Cole L, Camacho JA, Zhang Y, et al. Immune cell subset differentiation and tissue inflammation. J Hematol Oncol. 2018;11:97.

4. Libby P. Inflammatory mechanisms: the molecular basis of inflammation and disease. Nutr Rev. 2008;65:S140-6.

5. Ahmed A, Williams B, Hannigan G. Transcriptional activation of inflammatory genes: mechanistic insight into selectivity and diversity. Biomolecules. 2015;5:3087-111.

6. Smale ST, Natoli G. Transcriptional control of inflammatory responses. Cold Spring Harb Perspect Biol. 2014;6:a016261-a016261.

7. Liu T, Zhang L, Joo D, Sun S-C. NF-kB signaling in inflammation. Signal Transduct Target Ther. 2017;2:17023.

8. Villarino AV, Kanno Y, Ferdinand JR, O'Shea JJ. Mechanisms of Jak/STAT signaling in immunity and disease. J Immunol. 2015;194:21-7.

9. Atri C, Guerfali F, Laouini D. Role of human macrophage polarization in inflammation during infectious diseases. Int J Mol Sci. 2018;19:1801.

10. Murray PJ. Macrophage polarization. Annu Rev Physiol. 2017;79:541-66.

11. Larigot $L$, Juricek $L$, Dairou J, Coumoul X. AhR signaling pathways and regulatory functions. Biochim Open. 2018;7:1-9.

12. Tugal D, Liao X, Jain MK. Transcriptional control of macrophage polarization. Arterioscler Thromb Vasc Biol. 2013;33:1135-44.

13. Matthews J, Gustafsson J-Å. Estrogen receptor and aryl hydrocarbon receptor signaling pathways. Nucl Recept Signal. 2006;4:nrs.04016.

14. Ricote M, Glass CK. PPARs and molecular mechanisms of transrepression. Biochim Biophys Acta - Mol Cell Biol Lipids. 2007;1771:926-35.

15. Varga T, Czimmerer Z, Nagy L. PPARs are a unique set of fatty acid regulated transcription factors controlling both lipid metabolism and inflammation. Biochim Biophys Acta Mol Basis Dis. 2011;1812:1007-22.

16. Ma Y, Shi M, Wang Y, Liu J. PPAR Y and its agonists in chronic kidney disease. Int J Nephrol. 2020:2020:1-10.

17. Safe $\mathrm{S}$, Cheng $\mathrm{Y}$, Jin U-H. The aryl hydrocarbon receptor (AhR) as a drug target for cancer chemotherapy. Curr Opin Toxicol. 2017;2:24-9.

18. Bar-Or D, Salottolo KM, Loose H, Phillips MJ, McGrath B, Wei N, et al. A Randomized Clinical Trial to Evaluate Two Doses of an Intra-Articular Injection of LMWF-5A in Adults with Pain Due to Osteoarthritis of the Knee. Chopra A, editor. PLoS One. 2014;9:e87910.

19. Salottolo K, Cole B, Bar-Or D. Intra-articular injection of the anti-inflammatory compound LMWF-5A in adults with severe osteoarthritis: a doubleblind prospective randomized controlled multi-center safety and efficacy trial. Patient Saf Surg. 2018;12:11.

20. Schwappach J, Dryden SM, Salottolo KM. Preliminary trial of Intra-articular LMWF-5A for osteoarthritis of the Knee. Orthopedics. 2017:40:e49-53.

21. Schwappach J, Schultz J, Salottolo K, Bar-Or D. Incidence of total knee replacement subsequent to intra-articular injection of the anti-inflammatory compound LMWF-5A versus saline: a long-term follow-up study to a randomized controlled trial. Patient Saf Surg. 2018;12:14.

22. Thomas GW, Rael LT, Mains CW, Slone D, Carrick MM, Bar-Or R, et al. Anti-inflammatory activity in the low molecular weight fraction of commercial human serum albumin (LMWF5A). J Immunoass Immunochem. 2016:37:55-67.

23. Thomas GW, Rael LT, Hausburg M, Frederick ED, Mains CW, Slone D, et al. The low molecular weight fraction of human serum albumin upregulates production of $15 d-P G J 2$ in peripheral blood mononuclear cells. Biochem Biophys Res Commun. 2016;473:1328-33.

24. Rael LT, Bar-Or R, Banton KL, Mains CW, Roshon M, Tanner AH, et al. The anti-inflammatory effect of LMWF5A and N-acetyl kynurenine on macrophages: Involvement of aryl hydrocarbon receptor in mechanism of action. Biochem Biophys Rep. 2018;15:61-7.

25. Bar-Or D, Thomas GW, Rael LT, Gersch ED, Rubinstein P, Brody E. Low molecular weight fraction of commercial human serum albumin induces morphologic and transcriptional changes of bone marrow-derived mesenchymal stem cells. Stem Cells Transl Med. 2015;4:945-55.

26. Hausburg MA, Frederick ED, McNair P, Schwappach J, Banton KL, Roshon $M$, et al. Clinically relevant redifferentiation of fibroblast-like chondrocytes into functional chondrocytes by the low molecular weight fraction of human serum albumin. Clin Exp Rheumatol. 2018;36:891-5. 
27. Chen EY, Tan CM, Kou Y, Duan Q, Wang Z, Meirelles G, et al. Enrichr: interactive and collaborative HTML5 gene list enrichment analysis tool. BMC Bioinformatics. 2013;14:128.

28. Kuleshov MV, Jones MR, Rouillard AD, Fernandez NF, Duan Q, Wang Z, et al. Enrichr: a comprehensive gene set enrichment analysis web server 2016 update. Nucleic Acids Res. 2016;44:W90-7.

29. Keenan AB, Torre D, Lachmann A, Leong AK, Wojciechowicz ML, Utti $\checkmark$, et al. ChEA3: transcription factor enrichment analysis by orthogonal omics integration. Nucleic Acids Res. 2019:47:W212-24

30. Lee W, Kim HS, Hwang SS, Lee GR. The transcription factor Batf3 inhibits the differentiation of regulatory T cells in the periphery. Exp Mol Med. 2017;49:e393-e393.

31. Christian F, Smith E, Carmody R. The Regulation of NF-kB Subunits by Phosphorylation. Cells. 2016;5:12.

32. Liberato MV, Nascimento AS, Ayers SD, Lin JZ, Cvoro A, Silveira RL, et al. Medium Chain Fatty Acids Are Selective Peroxisome Proliferator Activated Receptor (PPAR) y Activators and Pan-PPAR Partial Agonists. Moschetta A, editor. PLoS One. 2012;7:e36297.

33. Hörhold F, Eisel D, Oswald M, Kolte A, Röll D, Osen W, et al. Reprogramming of macrophages employing gene regulatory and metabolic network models. Wallqvist A, editor. PLOS Comput Biol. 2020;16:e1007657.

34. Bright JJ, Kanakasabai S, Chearwae W, Chakraborty S. PPAR Regulation of inflammatory signaling in CNS diseases. PPAR Res. 2008;2008:1-12.

35. Quintana FJ. The aryl hydrocarbon receptor: a molecular pathway for the environmental control of the immune response. Immunology. 2013;138:183-9.

36. Rothhammer V, Borucki DM, Kenison JE, Hewson P, Wang Z, Bakshi R, et al. Detection of aryl hydrocarbon receptor agonists in human samples. Sci Rep. 2018;8:4970.

37. Ma J-J, Zhang T, Fang N, Zou Y, Gong Q-H, Yu L-M, et al. Establishment of a cell-based drug screening model for identifying agonists of human peroxisome proliferator-activated receptor gamma (PPAR Y). J Pharm Pharmacol. 2012:64:719-26.

38. Anraku M, Tsurusaki Y, Watanabe H, Maruyama T, Kragh-Hansen U, Otagiri M. Stabilizing mechanisms in commercial albumin preparations: octanoate and $\mathrm{N}$-acetyl---tryptophanate protect human serum albumin against heat and oxidative stress. Biochim Biophys Acta Proteins Proteomics. 2004;1702:9-17.

39. Ikuta T, Eguchi H, Tachibana T, Yoneda Y, Kawajiri K. Nuclear localization and export signals of the human aryl hydrocarbon receptor. J Biol Chem. 1998;273:2895-904.

40. Gutiérrez-Vázquez C, Quintana FJ. Regulation of the immune response by the aryl hydrocarbon receptor. Immunity. 2018;48:19-33.

41. Puga A, Barnes SJ, Chang C, Zhu H, Nephew KP, Khan SA, et al. Activation of transcription factors activator protein-1 and nuclear factor-kB by 2,3,7,8-Tetrachlorodibenzo-p-dioxin. Biochem Pharmacol. 2000:59:997-1005.

42. Ruby CE, Leid M, Kerkvliet NI. 2,3,7,8-Tetrachlorodibenzo- p-dioxin suppresses tumor necrosis factor-a and anti-CD40-induced activation of NF-KB/Rel in dendritic cells: p50 homodimer activation is not affected. Mol Pharmacol. 2002:62:722-8.

43. Vogel CFA, Khan EM, Leung PSC, Gershwin ME, Chang WLW, Wu D, et al. Cross-talk between aryl hydrocarbon receptor and the inflammatory response. J Biol Chem. 2014;289:1866-75.

44. Vogel CFA, Sciullo E, Li W, Wong P, Lazennec G, Matsumura F. RelB, a new partner of aryl hydrocarbon receptor-mediated transcription. Mol Endocrinol. 2007;21:2941-55.

45. Kimura A, Naka T, Nakahama T, Chinen I, Masuda K, Nohara K, et al. Aryl hydrocarbon receptor in combination with Stat1 regulates LPS-induced inflammatory responses. J Exp Med. 2009;206:2027-35.

46. Hanieh $\mathrm{H}$. Toward understanding the role of aryl hydrocarbon receptor in the immune system: current progress and future trends. Biomed Res Int. 2014;2014:1-14.
47. Nguyen NT, Hanieh H, Nakahama T, Kishimoto T. The roles of aryl hydrocarbon receptor in immune responses. Int Immunol. 2013;25:335-43.

48. Bessede A, Gargaro M, Pallotta MT, Matino D, Servillo G, Brunacci C, et al. Aryl hydrocarbon receptor control of a disease tolerance defence pathway. Nature. 2014;511:184-90.

49. Croasdell A, Duffney PF, Kim N, Lacy SH, Sime PJ, Phipps RP. PPAR Y and the innate immune system mediate the resolution of inflammation. PPAR Res. 2015;2015:1-20.

50. Delerive P, Martin-Nizard F, Chinetti G, Trottein F, Fruchart J-C, Najib J, et al. Peroxisome proliferator-activated receptor activators inhibit thrombininduced endothelin-1 production in human vascular endothelial cells by inhibiting the activator protein-1 signaling pathway. Circ Res. 1999:85:394-402.

51. Chung SW, Kang BY, Kim SH, Pak YK, Cho D, Trinchieri G, et al. Oxidized low density lipoprotein inhibits interleukin-12 production in lipopolysaccharide-activated mouse macrophages via direct interactions between peroxisome proliferator-activated receptor- $\gamma$ and nuclear factor-kB. J Biol Chem. 2000;275:32681-7.

52. Ricote M, Li AC, Willson TM, Kelly CJ, Glass CK. The peroxisome proliferator-activated receptor- $\gamma$ is a negative regulator of macrophage activation. Nature. 1998;391:79-82.

53. Natarajan C, Bright JJ. Peroxisome proliferator-activated receptor-gamma agonists inhibit experimental allergic encephalomyelitis by blocking IL-12 production, IL-12 signaling and Th1 differentiation. Genes Immun. 2002:3:59-70

54. Zingarelli B, Sheehan M, Hake PW, O'Connor M, Denenberg A, Cook JA. Peroxisome proliferator activator receptor- $\gamma$ ligands, 15-Deoxy- $\triangle 12,14$ -prostaglandin $\mathrm{J} 2$ and Ciglitazone, reduce systemic inflammation in polymicrobial sepsis by modulation of signal transduction pathways. J Immunol. 2003;171:6827-37.

55. Ferreira AE, Sisti F, Sônego F, Wang S, Filgueiras LR, Brandt S, et al. PPAR- $\gamma /$ IL-10 axis inhibits MyD88 expression and ameliorates murine polymicrobial sepsis. J Immunol. 2014;192:2357-65.

56. Hasegawa-Moriyama M, Kurimoto T, Nakama M, Godai K, Kojima M, Kuwaki T, et al. Peroxisome proliferator-activated receptor-gamma agonist rosiglitazone attenuates inflammatory pain through the induction of heme oxygenase-1 in macrophages. Pain. 2013;154:1402-12.

57. Uchiyama M, Shimizu A, Masuda Y, Nagasaka S, Fukuda Y, Takahashi H. An ophthalmic solution of a peroxisome proliferator-activated receptor gamma agonist prevents corneal inflammation in a rat alkali burn model. Mol Vis. 2013;19:2135-50.

58. Huang JT, Welch JS, Ricote M, Binder CJ, Willson TM, Kelly C, et al. Interleukin-4-dependent production of PPAR- $\gamma$ ligands in macrophages by 12/15-lipoxygenase. Nature. 1999;400:378-82.

59. Barish GD, Downes M, Alaynick WA, Yu RT, Ocampo CB, Bookout AL, et al. A nuclear receptor atlas: macrophage activation. Mol Endocrinol. 2005; 19:2466-77.

60. Shimonkevitz R, Thomas G, Slone DS, Craun M, Mains C, Bar-Or D. A diketopiperazine fragment of human serum albumin modulates t-lymphocyte cytokine production through Rap1. J Trauma Inj Infect Crit Care. 2008;64:35-41.

61. Thomas GW, Rael LT, Hausburg M, Frederick ED, Brody E, Bar-Or D. The low molecular weight fraction of commercial human serum albumin induces acetylation of a-tubulin and reduces transcytosis in retinal endothelial cells. Biochem Biophys Res Commun. 2016;478:1780-5.

\section{Publisher's Note}

Springer Nature remains neutral with regard to jurisdictional claims in published maps and institutional affiliations. 